\title{
DESJUDICIALIZAÇÃO - ALTERNATIVA VIÁVEL À EFETIVAÇÃO DO DIREITO À SAÚDE
}

\section{DEJUDICIALIZATION - A VIABLE ALTERNATIVE TO THE REALIZATION OF THE RIGHT TO HEALTH}

\author{
Sandra Regina Martin ${ }^{1}$ Ana Luísa Michelon² \\ Joana D'Arc de Moraes Malheiros ${ }^{3}$
}

DOI: https://doi.org/10.37767/2591-3476(2020)06

\begin{abstract}
RESUMEN:
Este artículo busca demostrar que existen otras formas de acceso a la justicia para consagrar el derecho a la salud, y que el fenómeno de la desjudicialización es una excelente alternativa para que las personas ejerzan sus derechos con total seguridad jurídica. Es el ejercicio del derecho a favor de la vida. Prueba de ello son los resultados positivos logrados al mediar conflictos en lugar de presentar una demanda, así como al instrumentalizar varios actos legales en notarios extrajudiciales y cámaras privadas de conciliación y mediación. La metodología utilizada fue la investigación bibliográfica de autores de renombre que comenzaron a desarrollar formas de resolución de disputas, sin la necesidad de activar el poder judicial, se realizó una investigación exploratoria en doctrina y legislación, utilizando el método deductivo. La investigación es extremadamente importante porque analiza un tema actual, que tiene repercusiones en las esferas legal y social.
\end{abstract}

\section{RESUMO:}

Esse artigo busca demonstrar que existem outras formas de acesso à justiça para consagrar o direito à saúde, e que o fenômeno da desjudicialização é uma excelente alternativa para que o indivíduo exerça seus direitos com plena segurança jurídica. É o exercício do direito em favor da vida. Prova disso são os resultados positivos alcançados com a mediação de conflitos, em vez do ajuizamento de uma demanda judicial, e como com a instrumentalização de diversos atos jurídicos nos cartórios extrajudiciais e nas Câmaras Privadas de Conciliação e Medição. A metodologia utilizada foi a pesquisa bibliográfica de renomados autores que passaram a desenvolver formas de solução de litígios, sem a necessidade de se acionar o Poder Judiciário, realizou-se pesquisa de cunho exploratório em doutrina e legislação, valendo-se do método dedutivo. A pesquisa é de suma impor-

\footnotetext{
1 Professora Produtividade CNPq, Pós Doutora em Direto pela Università de Roma Tre, Pós Doutora em Política Públicas pela Università do Salento. Professora e Coordenadora do Mestrado em Direitos Humanos da UniRitter e Professora Visitante no PPGDIR/UFRGS. Email: srmartini@terra.com.br. ORCID iD: https://orcid.org/0000-0002-5437-648X

2 Mestranda em Direitos Humanos da UniRitter - Laureate Internacional Universities. Bolsista CAPES. Especialização em Direito Público. Fundação Escola Superior do Ministério Público - RS, FESMP/RS, Brasil. E-mail: anamichelon@hotmail.com. ORCID iD: https://orcid.org/0000-0002-9825-9322.

3 Mestranda em Direitos Humanos da UniRitter - Laureate Internacional Universities. Especialização em Direito Notarial e Registral. Universidade de Passo Fundo - RS UPF/RS, Brasil. MBA Gestão em Serviços Notariais e Registrais FGV Porto Alegre/RS, Brasil. E-mail: joana.malheiros@hotmail.com. ORCID iD: https://orcid.org/0000-0002-1736-6338.
} 
tância porque analisa um tema atual, que repercute nos âmbitos jurídicos e sociais.

\begin{abstract}
This article seeks to demonstrate that there are other forms of access to justice to consecrate the right to health, and that the phenomenon of dejudicialization is an excellent alternative for individuals to exercise their rights with full legal certainty. It is the exercise of law in favor of life. Proof of this is the positive results achieved by mediating conflicts rather than filing a lawsuit, as well as by instrumentalizing various legal acts in extrajudicial notaries and private conciliation and metering chambers. The methodology used was the bibliographic research of renowned authors who began to develop forms of dispute resolution, without the need to trigger the judiciary, was conducted exploratory research in doctrine and legislation, using the deductive method. The research is extremely important because it analyzes a current theme, which has repercussions in the legal and social spheres.
\end{abstract}

PALABRAS CLAVE: Litigio; Desjudicialización; Mediación; Mediación en salud; Derecho a la salud.

PALAVRAS-CHAVE: Litigiosidade; Desjudicialização; Mediação; Mediação Sanitária; Direito à saúde.

KEY WORDS: Litigation; Dejudicialization; Mediations; Health Mediation; Right to Health

\title{
I. Introdução
}

O presente estudo aborda as formas de se buscar a solução de conflitos de forma alternativa ao modelo jurisdicional tradicional. Como as relações humanas na contemporaneidade estão abaladas, é crescente a judicialização das demandas. Ante um sistema clássico que não consegue muitas vezes compreender em sua totalidade as problemáticas apresentadas, a sociedade demanda a implantação de um sistema flexível, que ajuste as condutas humanas de uma forma qualitativa, e não apenas quantitativa. As questões de enfrentamento devem, pois, ser analisadas em sua complexidade para a resolução eficiente do litígio.

Buscamos analisar o conflito e entender o que torna a mediação sanitária instrumento social de pacificação e os elementos que serão necessários para a obtenção do sucesso na sua aplicação, por exemplo a mudança de postura dos profissionais do direito, dos profissionais da saúde e da cultura dependente da sociedade em relação ao Poder Judiciário na solução de conflitos.

\section{Importância da desjudicialização na área da saúde}

A mediação sanitária é uma nova forma de acesso à Justiça que se utiliza de inovadoras ferramentas para a solução de conflitos, e pode ser operacionalizada tanto nas Câmaras Privadas de Mediação e Conciliação, quanto nos Cartórios Extrajudiciais. Antes de discorrermos sobre a relevância da desjudicialização na área da saúde, convém trazer à lume sua conceituação, para sobrepor à judicialização das questões de vigilância sanitária. 
Segundo Eber Zoehler Santa Helena, "o termo desjudicialização diz respeito à propriedade de facultar às partes comporem seus conflitos fora da esfera judicial, desde que sejam juridicamente capazes e que tenham por objeto direitos disponíveis", porém com maior celeridade, economia e com a mesma segurança jurídica, eis que os acordos são chancelados pelo Estado, por meio da atuação dos cartórios extrajudiciais e/ou das Câmaras Privadas de Mediação e Conciliação. ${ }^{4}$

Em nossa sociedade, inúmeros são os exemplos a justificar esta prática, que vêm apresentando resultados positivos para a redução do acionamento do judiciário. Para tanto, houve uma ampliação dos serviços oferecidos pelos cartórios extrajudiciais, com evidente crescimento qualitativo na sua prestação, bem como a ampliação do número de Câmaras Privadas de Mediação e Conciliação, com atuação nas mais diversas áreas do conhecimento, no intuito de buscar soluções pacíficas, que impeçam o ajuizamento de demandas judiciais.

Essa ampliação é um investimento para que o Poder Judiciário possa exercer efetivamente o seu papel capital na composição das relações sociais, políticas, jurídicas, econômicas, dentre outras, suprindo os anseios de justiça do cidadão brasileiro na via judicial.

Há um crescimento exacerbado de ações judiciais, que acaba por congestionar o Poder Judiciário, deixando os direitos de muitos cidadãos sem a devida efetivação, por múltiplas causas, quer nas esferas legislativa e executiva. Tal assertiva vem reproduzida por pesquisas a seguir mencionadas na situação que ora colacionamos: "ao se lançar um olhar sobre a realidade nacional, constata-se que a judicialização da saúde não conseguiu dar uma resposta efetiva à sociedade". Esta constatação foi alcançada a partir da leitura dos relatórios produzidos pelo Observatório de Análise Política em Saúde (OAPS, 2017), que retrata o crescente aumento do número das ações judiciais e o descompasso com a efetivação do direito na prática. ${ }^{5}$

$\mathrm{O}$ acesso à justiça é um direito fundamental insculpido no artigo $5^{\circ}, \mathrm{XXXV}^{6}$ de nossa Constituição Cidadã. Dessa maneira, cabe ao Estado, através do Poder Judiciário, promover os meios adequados para que todos os cidadãos possam resolver seus litígios e demais atos, que dependam da tutela jurisdicional, de forma eficiente em um tempo razoável, conforme se vislumbra pela leitura do artigo $5^{\circ}$, LXXIV7 da mesma Carta Constitucional.

Existe, pois, um comando constitucional para concretizar um dos direitos mais prementes do ser humano, o acesso a justiça Tal garantia é abalada com a eclosão excessiva de processos judiciais. O desenvolvimento humano em vários setores - econômico, social, político, religioso, entre outros - faz fomentar a competição, a concorrência, o individualismo, e que acaba por gerar uma sociedade conflituosa a clamar por uma solução, a qual o Estado, através de seus órgãos judiciais, não consegue operacionalizar de forma eficiente e dentro de um prazo razoável. Hoje, o dito popular “a justiça tarda,

\footnotetext{
4 HELENA, Eber Zoehler Santa (2006). "O fenômeno da desjudicialização" en Revista Jus Navigandi, año 11, Nro. 922. Tomado de: https://jus.com.br/ artigos/7818. 29.07.2019.

5 MACHADO, Clara (2017). O princípio jurídico da fraternidade, Lumen Juris, Rio de Janeiro.

6 Art.5 XXXV - a lei não excluirá da apreciação do Poder Judiciário lesão ou ameaça a direito.

7 Art.5 LXXIV - o Estado prestará assistência jurídica integral e gratuita aos que comprovarem insuficiência de recursos.
} 
mas não falha" não é mais admissível, uma vez que a demora no desenrolar de uma demanda não satisfaz os ideais de eficiência da atividade jurisdicional, provocando descrédito e desprezo do cidadão comum pela justiça.

Neste contexto de crise do poder judiciário, faz-se necessária a implementação de políticas públicas com novos métodos de acesso à justiça, como meios alternativos para solução de conflitos, ou mesmo atos civis, gerados entre os cidadãos em suas mais diversas formas de relacionamento social. Entre estes novos métodos, que importam na geração do fenômeno da desjudicialização, cabe especial destaque às normativas editadas, a Resolução 125/2010 do CNJ, com posterior publicação da Lei 13.140/2015 e mais recentemente o Provimento 67 de 26 de março de 2018, também pelo CNJ. São legislações que permitem a mediação e conciliação, e já despontam nos cartórios extrajudiciais em alguns estados da Federação e nas Câmaras Privadas de Conciliação e Mediação, como uma maneira de implementar políticas públicas e fomentar a cultura da paz.

As medidas alternativas na resolução de conflitos na área da vigilância sanitária precisam ser efetivadas a fim de garantir um dos direitos mais prementes do cidadão insculpidos na magna carta de 1988, o direito à saúde. É neste contexto que surge a desjudicialização, de acordo com as palavras da douta pesquisadora: "necessário, portanto, avaliar se o fenômeno inverso, ou seja, o da desjudicialização seria uma alternativa viável à concretização do direito à saúde na medida em que propugna diálogos interinstitucionais, mediações administrativas e uma maior participação da sociedade nas tomadas de decisão". ${ }^{\prime}$

A perquirir este viés da desjudicialização da saúde, apresenta-se a mediação sanitária, a ser operacionalizada tanto nos cartórios extrajudiciais, quanto nas Câmaras Privadas de Conciliação e Mediação, como uma resposta positiva a ser explorada em prol do cidadão, sobre a qual passamos a discorre.

\section{Mediação sanitária}

A mediação sanitária é um processo de colaboração para resolução ou manejo de conflitos, em que duas ou mais partes que se encontram em litígio são apoiadas por uma ou mais terceiras partes imparciais (mediadores), com o objetivo de as primeiras se comunicarem entre elas para chegarem à sua própria solução. Sem imposição de sentenças ou de laudos e com profissional devidamente formado, as partes são auxiliadas a acharem seus verdadeiros interesses e a preservá-los num acordo criativo em que as duas saiam vitoriosas. ${ }^{10}$

Os mediandos recorrem a um terceiro imparcial, o mediador, para estabelecer o vínculo entre eles, facilitar o diálogo, conduzir progressivamente o objeto da problemática, escolher as alternativas de solução, definir ou não a solução do conflito. Nesse sentido, tendo como premissa a humanização do processo de mediação, aponta Vasconcelos ${ }^{11}$

\footnotetext{
8 BRASIL. Presidência da República. Casa Civil. Subchefia para Assuntos Jurídicos. (2015) Lei 13.140, de 26 de junho de 2015. Diário Oficial [da] União, Brasília. Tomado de: http://www.planalto.gov.br/ccivil_03/_ato2015-2018/2015/lei/113140.htm. 04.07. 2019.

9 MACHADO, Clara \& MARTINI, Sandra Regina (2018). "Desjudicialização da saúde, diálogos interinstitucionais e participação social: em busca de alternativas para o sistema" en REI - Revista Estudos Institucionais, v. 4, Nro. 2, pp. 774-796. Tomado de: https://www.estudosinstitucionais.com/REI/article/ view/190. 24.08.2019. p. 780.

10 VEZZULA, Juan Carlos (2001). Mediação: guia para usuários e profissionais, IMAB, São Paulo.

11 VASCONCELOS, Carlos Eduardo (2017). Mediação de conflitos e práticas restaurativas, Forense, Rio de Janeiro, Método, São Paulo.
} 
que o mediador colabora com os mediandos para que eles pratiquem uma comunicação construtiva, identifiquem seus interesses e necessidades comuns. Spengler ${ }^{12}$ também $^{2}$ sinaliza a importância do mediador para tornar as relações humanizadas no conflito. Segundo a autora, o mediador conduz as partes a chegar "em uma solução aceitável e estruturada de maneira que permita ser possível a continuidade das relações entre as pessoas involucradas no conflito".

Convocando outra ótica na concretização da justiça, a mediação é um resgate da sensibilidade, da experiência do ser humano no seu caráter plural. Nas palavras de Warat ${ }^{13}$ "é um processo que facilita, com a ajuda de um mediador, a interpretação ${ }^{14}$ entre as partes, trabalhando segredos do que foi enunciado como pretensão, interpretando a história do conflito, para produzir uma diferença, por seu reconhecimento em uma inscrição simbólica com o outro".

A busca pelo consenso pode ser o ápice da mediação sanitária. A ideia de vencedor ou perdedor passa a ser substituída por uma decisão em que todos os envolvidos são ganhadores. Estudos, de forma eficaz, têm demonstrado que é possível em situações conflituosas chegar a um consenso. Na Teoria do Equilíbrio de Nash, teoria dos jogos não competitivos, são demonstradas situações em que um jogador não precisa derrotar o outro para sair vitorioso; muitas vezes um depende do outro para obter o melhor resultado ${ }^{15}$. Essa teoria é estudada, entre outros casos, a partir do clássico jogo cooperar e trair, dilema do prisioneiro ${ }^{16}$, que evidencia a dificuldade que se tem para manter a cooperação em situações de tensão. Nesse caso emblemático, é possível identificar que, mesmo em uma situação de muita pressão, há um caminho possível para a solução do conflito: mediação que não foca como se joga, e sim os mecanismos disponíveis para a análise sobre os conflitos de interesse.

A teoria dos jogos desvenda a dinâmica dos conflitos de interesse, verificando as tendências entre os jogadores de maximizar o ganho individual e substituindo-o por um agir altruísta. Os interesses deixam, assim, de ser conflitantes porque é vantajoso para todos colaborar. Neste sentido, o modelo teórico proposto por Nash prioriza o caráter cooperativo em uma dinâmica conflituosa por meio de uma tática altruísta, pois objetiva a reciprocidade de estratégias em prol do melhor resultado para ambos os jogadores. Na medida em que a mediação busca o tratamento do conflito com vistas à satisfação por parte de todos os envolvidos, perceber o equilíbrio de Nash pode significar o ponto chave para se chegar ao consenso.

A teoria do equilíbrio de Nash contribuiu significativamente na garantia dos pressupostos da mediação, na medida em que, para reestabelecer o diálogo em um conflito, basear decisões na decisão do outro é um método de cooperação para que no

\footnotetext{
12 SPENGLER, Fabiana Marion (2016). Da jurisdição à mediação: por uma outra cultura no tratamento de conflitos, Unijuí, Ijuí, p. 179.

13 WARAT, Luis Alberto (2004). Surfando na pororoca: ofício do mediador, Fundação, Boiteux, Florianopólis, p. 64.

14 Interpretar aqui pretende fazer referência à produção conjunta de uma diferença longe de qualquer tentativa de dominação. WARAT, Luis Alberto (2004): Op. Cit., p.64.

15 D’ANTONIO, Suzete Souza (2016). "Mediação Sanitária: diálogo e consenso possível" en Revista Cadernos Ibero-Americanos de Direito Sanitário, v. 5, nro. 2, pp. 8-22. Tomado de: https://www.cadernos.prodisa.fiocruz.br/index.php/cadernos/article/view/255. 31.07.2019.

16 Dilema do prisioneiro. É um jogo que representa bem o dilema entre cooperar e trair. Dois suspeitos, A e B, são presos pela polícia. A polícia não tem provas suficientes para condená-los, então separa os prisioneiros em salas diferentes e oferece a ambos o mesmo acordo: a) Se um dos prisioneiros confessar (trair o outro) e o outro permanecer em silêncio, o que confessou sai livre enquanto o cúmplice silencioso cumpre 10 anos. b) Se ambos ficarem em silêncio (colaborarem um com ou outro), a polícia só pode condená-los a um ano cada um. c) Se ambos confessarem (traírem o comparsa), cada um leva cinco anos de cadeia. D’ANTONIO, Suzete Souza (2016): Op. Cit., p.10.
} 
final o resultado do conflito seja satisfatório.

Na teoria dos jogos, assim como na mediação, a identificação dos processos construtivos do litígio pressupõe a observação dos fatos sob diversas lentes: "[...] primeiro, são usadas as lentes para examinar a situação imediata; em seguida, outras lentes são utilizadas para ver o passado dos problemas imediatos e os padrões das relações que demarcam o conflito (avaliação aprofundada da situação vivida); e, por último, é utilizada a lente para encontrar um marco de convergência com o qual se possa criar uma base de atuação para que os indivíduos envolvidos possam discutir o conteúdo, o contexto e as estruturas das relações de forma cooperativa - aqui eles começam a buscar respostas ou soluções criativas ${ }^{\prime \prime 7}$.

Todavia, os aspectos que se referem ao paradigma posto em questão ainda não se impõem. Grande parte dos conflitos são entendidos e tratados de forma diferente pelo Poder Judiciário, valorizando a imperatividade das decisões do Estado-juiz. Nesse sentido, o juiz Alexandre Rosa ao prefaciar o livro de Warat ${ }^{18}$ alerta que o conflito "no modelo estatal é manifestado pelo litígio, forma legalmente convencionada, segundo a qual o Estado-juiz aponta a decisão correta: a lei no caso particular. Entretanto com essa visão, o conflito é desqualificado e varrido para debaixo desse remédio-simulacro chamado processo'. 'Os protagonistas são os advogados, juízes, promotores que contentam-se com a resolução na forma da lei sem qualquer ponte para o futuro'".

Em tal percepção, em que a solução para o conflito é sentenciada por um terceiro, os conflitos não são dirimidos porque a forma de resolução escolhida não permite a coexistência de interesses.

Indaga Warat ${ }^{19}$ : "resolveu o conflito? Será que realmente as funções manifestas são prometidas? As funções prometidas são maquiadas pelo litígio e resolvidas(!?) sem que as partes entendam nada".

Os questionamentos de Warat evidenciam a necessidade de se buscar por uma justiça social para o tratamento de conflitos, entendendo-os como uma oportunidade para o crescimento e a maturação das relações, e tratando interesses das partes envolvidas de forma dialógica, pacífica e consensual.

Ainda considera Spengler ${ }^{20}$ que "a mediação difere das práticas tradicionais de jurisdição justamente porque o seu local de trabalho é a sociedade, sendo a sua base de operações o pluralismo de valores, a presença de sistemas de vida diversos e alternativos; sua finalidade consiste em reabrir os canais de comunicação interrompidos e reconstruir laços sociais destruídos".

As autoras trazem como importante desafio da mediação "aceitar a diferença e a diversidade, o dissenso e a desordem por eles gerados". Além disso, consideram que "a principal ambição não consiste em propor novos valores, mas em restabelecer a

\footnotetext{
17 ANDRADE, Adriana Maria Amado da Costa de. (2014) A perspectiva sociológica da resolução de conflitos no estudo do comportamento frente às instituições. Tese (Doutorado em Sociologia) - Faculdade de Filosofia e Ciências Humanas da Universidade Federal de Minas Gerais, Minas Gerais, p.63. 18 WARAT, Luis Alberto (2004): Op. Cit., p. 11-12.

20 LUCAS, Doglas Cesar \& SPENGLER, Fabiana Marion (2011). Justiça restaurativa e mediação: políticas públicas no tratamento dos conflitos sociais, Unijuí, Ijuí, Brasil. p. 174.
} 
comunicação entre aqueles que cada um traz consigo"21.

Importa também saber como na mediação se concretizam as diferentes esferas do Direito, a complexidade e os aspectos subjetivos dos relacionamentos - menos hierarquizados e mais horizontalizados - envolvidos nos conflitos mediados.

\section{O conflito, cerne do procedimento de mediação sanitária}

Vimos que a mediação é um meio de resolução de conflitos alternativo ao processo judicial tradicional. $O$ instituto da mediação sanitária abarca diferentes espécies de conflitos na área da saúde - responde a conflitos como aqueles ocorridos entre médicos/ paciente, o SUS e seus usuários, em matéria de plano de saúde, entre a seguradora e o segurado ou beneficiário, conflitos por defeito na prestação do serviço de saúde.

O conceito de mediação sanitária recobre, portanto, contextos diferentes, lidando com conflitos interpessoais, sociais, entre outros. Para compreender realidades distintas entre si, o conceito de mediação deve ser flexível em seus sentidos e o mediador deve analisar o conflito em sua complexidade - tanto do ponto de vista daqueles que usufruem da saúde quanto daqueles que são responsáveis em garanti-la.

Nesse procedimento o mediador deve compreender as especificidades do conflito em que envolvam mediações sanitárias e os mediandos devem buscar a estabilização, valorização e igualdade. Sob essa perspectiva, as mediações são as conexões que se estabelecem entre as motivações, reações e reconfigurações da realidade. Segundo Chrispino 22 o conflito pode ser analisado como: "Porém, o mito de que o conflito é ruim está ruindo. O conflito começa a ser visto como uma manifestação mais natural e, por conseguinte, necessária às relações entre pessoas, grupos sociais, organismos políticos e Estados. O conflito é inevitável e não se devem suprimir seus motivos, até porque ele possui inúmeras vantagens dificilmente percebidas por aqueles que vêem nele algo a ser evitado: - Ajuda a regular as relações sociais; - ensina a ver o mundo pela perspectiva do outro; • permite o reconhecimento das diferenças, que não são ameaça, mas resultado natural de uma situação em que há recursos escassos, • ajuda a definir as identidades das partes que defendem suas posições; - permite perceber que o outro possui uma percepção diferente; - racionaliza as estratégias de competência e de cooperação; • ensina que a controvérsia é uma oportunidade de crescimento e de amadurecimento social".

Esse modelo de reflexão pode ser referência na análise dos conflitos sanitários: valoriza o conflito como fonte de ideias novas, leva a discussões até então não trazidas à luz do Direito Sanitário, permite a exploração de diferentes pontos de vista, interesses e valores recorrentes na área da saúde.

Com base nessas colocações, o conflito pode agir de maneira construtiva, estimulando o potencial inovador das pessoas. Na mesma linha de pensamento, Marcato e Tartuce ${ }^{23}$ analisam os conflitos "a partir de uma nova visão dos conflitos e de si mesmos, as pessoas poderão lidar melhor com seu panorama passado (resolvendo conflitos já existentes) e

21 LUCAS, Doglas Cesar \& SPENGLER, Fabiana Marion (2011): Op. Cit., p. 174.

22 CHRISPINO, Álvaro. (2007). "Gestão de conflito escolar: da classificação dos conflitos os modelos de mediação" en Ensaio: aval. Pol. Púb. Educ., v. 15, nro. 54, pp. 11-28. Tomado de: http://www.scielo.br/pdf/ensaio/v15n54/a02v1554.pdf. 31.07/2019.

23 MARCATO, Ana Cândida Menezes \& TARTUCE, Fernanda (2018). "Mediação no direito empresarial: possibilidades interessantes em conflitos securitários” en Revista de Processo, v. 279, pp. 513-527. Tomado de: http://www.fernandatartuce.com.br/wp-content/uploads/2018/05/ Media\%C3\%A7\%C3\%A3o-dir-empresarial-conflitos-securitarios-Ana-Marcato-e-Fernanda-Tartuce.pdf. 31.07.2019. p. 4. 
com suas perspectivas futuras (prevenindo a ocorrência de futuras querelas mediante uma abordagem mais consciente e reflexiva)".

Na mediação sanitária, o conflito merece ser analisado de maneira que possa contribuir para que "os indivíduos resgatem sua própria dignidade e assumam a responsabilidade pessoal"24. Moore 25 , ao classificar o conflito, indica as suas causas, permitindo que possa ser visto como oportunidade de transformação e crescimento a partir de uma visão mais completa e abrangente das relações entre os envolvidos.

Moore ${ }^{26}$ classifica os conflitos em estruturais, de valor, de relacionamento, de interesse e quanto aos dados. A partir dessa classificação, o mediador pode pensar o conflito em resposta a duas perguntas: o que o conflito muda? Que tipo de mudanças os mediandos buscam? Na primeira pergunta, busca-se reconhecer os padrões comuns e impactos do conflito social; na segunda, busca-se reconhecer a necessidade de identificar como nossos valores e intenções podem ser tão ativos para responder, intervir e criar mudanças. São dessas mudanças, diálogos cada vez mais profundos que provém a construção da paz necessária.

Em sua complexidade, a mediação sanitária também eleva o acolhimento da diversidade, encoraja relações baseadas na solidariedade, desconstrói e reconstrói relações polarizadas, buscando captar pontos que ligam as diferentes realidades subjacentes ao conflito entre as partes.

Redorta ${ }^{27}$ considerou que a tipologia de conflito é de tal importância, que ele dedicou toda uma obra a essa tarefa. É possível sintetizar a categorização dos tipos de conflito em de recursos escassos, de poder, de autoestima, de valores, de estrutura, de identidade, de norma, de expectativas, de inadaptação, de informação, de interesses, de atribuição, de relações pessoais, de inibição, de legitimação. ${ }^{28}$

Com base na análise do conflito, é possível o restabelecimento do diálogo e das diretrizes para uma comunicação. Somente a partir do diálogo será possível que a vontade de cada pessoa integre a solução alcançada, proporcionando a formação de um consenso não só quanto aos termos do acordo, mas quanto à sua concretização,

\footnotetext{
24 MARCATO, Ana Cândida Menezes \& TARTUCE, Fernanda (2018): Op. Cit., p. 4.

25 MOORE, C. W. (1998). O processo de mediação: estratégias práticas para a resolução de conflitos, ARTMED, Porto Alegre.

26 Estruturais - Padrões destrutivos de comportamento ou interação; controle, posse ou distribuição desigual de recursos; poder e autoridade desiguais; fatores geográficos, físicos ou ambientais que impeçam a cooperação; pressões de tempo. De Valor - Critérios diferentes para avaliar ideias ou comportamentos; objetivos exclusivos intrinsecamente valiosos; modos de vida, ideologia ou religião diferente. De Relacionamento - Emoções fortes; percepções equivocadas ou estereótipos; comunicação inadequada ou deficiente; comportamento negativo - repetitivo. De Interesse - Competição percebida ou real sobre interesses fundamentais (conteúdo); interesses quanto a procedimentos; interesses psicológicos. Quanto aos Dados - Falta de informação; informação errada; pontos de vista diferentes sobre o que é importante; interpretações diferentes dos dados; procedimentos de avaliação diferentes. MOORE, C. W. (1998): Op. Cit., p. 62 .

27 De recursos escassos - disputamos por algo que não existe suficientemente para todos; De poder - Disputamos porque algum de nós quer mandar, dirigir ou controlar o outro. De autoestima - Disputamos porque meu orgulho pessoal se sente ferido. De valores - Disputamos porque meus valores ou crenças fundamentais estão em jogo. De estrutura - Disputamos por um problema cuja solução requer longo prazo, esforços importantes de muitos, e meios estão além de minha possibilidade pessoal. De identidade - Disputamos porque o problema afeta minha maneira intima de ser o que sou. De norma - Disputamos porque meus valores ou crenças fundamentais estão em jogo. De expectativas - Disputamos porque não se cumpriu ou se fraudou o que um esperava do outro. De expectativas - Disputamos porque não se cumpriu ou se fraudou o que um esperava do outro. De inadaptação - Disputamos porque modificar as coisas produz uma tensão que não desejo. De informação - Disputamos por algo que se disse ou não se disse ou que se entendeu de forma errada. De interesses - Disputamos porque meus interesses ou desejos são contrários aos do outro. De atribuição - Disputamos porque o outro não assume a sua culpa ou responsabilidade em determinada situação. De relaçães pessoais - Disputamos porque habitualmente não nos entendemos como pessoas. De inibição - Disputamos porque claramente a solução do problema depende do outro. De legitimação - Disputamos porque o outro não está de alguma maneira autorizado a atuar como o faz, ou tem feito ou pretende fazer.
}

28 REDORTA, J. (2004) Cómo analizar los conflictos: la tipologia de conflictos como herramienta de mediación, Edicones Paidós Ibérica, Barcelona. 
assim ensejando o cumprimento espontâneo do ajuste. O dissenso passa a ser visto como uma oportunidade de transformação e crescimento, porque contempla uma visão mais completa e abrangente das relações entre os envolvidos.

Em regra, as partes não estão conscientes da existência ou do potencial que o conflito exerce sobre elas; cabe, desse modo, aos mediadores identificar na disputa os posicionamentos segundo as necessidades requeridas, a intensidade das emoções, os interesses das partes envolvidas. O ponto chave é fazer com que as partes percebam necessidades ocultas de identidade, segurança e pertencimento, e possam usá-las para redefinir suas posições, atingindo de fato seus reais interesses. Esse mapeamento representa o desafio de como terminar algo não desejado e como construir algo que é desejado.

Neste objetivo é preciso reconhecer que a vida é o maior bem do ser humano, e que conflitos na área da saúde lidam com problemáticas que extrapolam uma lógica meramente jurídico. Isso não significa resolver qualquer conflito ou parte de um conflito específico que possa impactar na promoção da saúde, mas transformar a forma como as pessoas lidam com seus conflitos - ou seja, como podem se aproximar e lidar com eles de uma forma mais ampla e positiva -, e como a sociedade se enriquece com essa transformação: cada uma das partes pertence a uma corrente que estabelece o todo a partir desse entendimento. Dessa vinculação depende o movimento da vida que se quer equilibrada, assume-se a compreensão da saúde como direito fundamental.

\section{Considerações finais}

Diante da eclosão da litigiosidade na área da saúde, a desjudicialização tornou-se uma realidade no Brasil, devido à edição de leis que favorecem a composição amigável de situações sociais por meio dos serviços extrajudiciais. A desjudicialização acaba, desta forma, propiciando um alívio para o Poder Judiciário bem como assegurando ao cidadão o direito à saúde.

A desjudicialização transcende a natureza de mera política judicial, pois promove mudanças para a criação de meios autônomos de solução de conflitos de interesse, que asseguram não só a desburocratização, a efetividade, a celeridade e a segurança jurídica, como também a pacificação social e, acima de tudo, a boa fé.

Como possibilidade de desjudicialização, o presente artigo analisou a mediação com especial enfoque no conflito sanitário, porque tem força e habilidade socialmente destrutivas e aparentemente indiscutíveis. Não basta eliminar o conflito, nos ensina Warat, nas palavras do autor, eles nunca desaparecem; é preciso que se transformem intervindo sobre os sentimentos das pessoas, e não apenas sobre os conflito. Daí a recomendação de transformação da pessoa, na presença de um conflito pessoal, pois é no interior de cada indivíduo que se encontram os conflitos.

O conflito também foi analisado na perspectiva da Teoria de Nash; ficou demonstrado que o conflito poderá ser resolvido com maior facilidade, no momento em que as partes se conscientizam de que a cooperação é mais vantajosa para ambos, é nesse viés que se mostrou a importância da mediação para o benefício dos envolvidos.

O processo judicial leva à guerra, não à paz; assim, acaba por perpetuar o conflito e 
todos os sentimentos de angústias, rancores, dores e mágoas, que desconstroem o ser humano se visualizado numa perspectiva emocional saudável, podendo inclusive, em alguns casos, levá-lo à morte. E, o que é pior, sem a satisfação do direito que foi buscar em favor da vida.

Portanto, a adoção de meios alternativos, mediante a desjudicialização com a resolução de conflitos, está associada a processos e movimentos em que os próprios envolvidos são os protagonistas da composição. Somente a esses, cabe o direito de escolher a solução que mais Ihes convém como ser humano.

\section{REFERÊNCIAS BIBLIOGRÁFICAS}

- ANDRADE, Adriana Maria Amado da Costa de. (2014) A perspectiva sociológica da resolução de conflitos no estudo do comportamento frente às instituições. Tese (Doutorado em Sociologia) - Faculdade de Filosofia e Ciências Humanas da Universidade Federal de Minas Gerais, Minas Gerais.

- BRASIL. Presidência da República. Casa Civil. Subchefia para Assuntos Jurídicos. (2015) Lei 13.140, de 26 de junho de 2015. Diário Oficial [da] União, Brasília. Tomado de: http:// www.planalto.gov.br/ccivil_03/_ato2015-2018/2015/lei//13140.htm. 04.07. 2019.

- Chrispino, Álvaro. (2007). "Gestão de conflito escolar: da classificação dos conflitos os modelos de mediação" en Ensaio: aval. Pol. Púb. Educ., v. 15, nro. 54, pp. 11-28. Tomado de: http://www.scielo.br/pdf/ensaio/v15n54/a02v1554.pdf. 31.07/2019.

- D'ANTONIO, Suzete Souza (2016). "Mediação Sanitária: diálogo e consenso possível" en Revista Cadernos Ibero-Americanos de Direito Sanitário, v. 5, nro. 2, pp. 8-22. Tomado de: https://www.cadernos.prodisa.fiocruz.br/index.php/cadernos/article/view/255. 31.07.2019.

- HELENA, Eber Zoehler Santa (2006). "O fenômeno da desjudicialização" en Revista Jus Navigandi, año 11, Nro. 922. Tomado de: https://jus.com.br/artigos/7818. 29.07.2019.

- LUCAS, Doglas Cesar \& SPENGLER, Fabiana Marion (2011). Justiça restaurativa e mediação: políticas públicas no tratamento dos conflitos sociais, Unijuí, ljuí, Brasil.

- MACHADO, Clara (2017). O princípio jurídico da fraternidade, Lumen Juris, Rio de Janeiro. - MACHADO, Clara \& MARTINI, Sandra Regina (2018). “Desjudicialização da saúde, diálogos interinstitucionais e participação social: em busca de alternativas para o sistema" en REI - Revista Estudos Institucionais, v. 4, Nro. 2, pp. 774-796. Tomado de: https://www. estudosinstitucionais.com/REl/article/view/190. 24.08.2019.

- MARCATO, Ana Cândida Menezes \& TARTUCE, Fernanda (2018). “Mediação no direito empresarial: possibilidades interessantes em conflitos securitários" en Revista de Processo, v. 279, pp. 513-527. Tomado de: http://www.fernandatartuce.com.br/wp-content/uploads/2018/05/Media\%C3\%A7\%C3\%A3o-dir-empresarial-conflitos-securitariosAna-Marcato-e-Fernanda-Tartuce.pdf. 31.07.2019.

- MOORE, C. W. (1998). O processo de mediação: estratégias práticas para a resolução de conflitos, ARTMED, Porto Alegre.

- REDORTA, J. (2004) Cómo analizar los conflictos: la tipologia de conflictos como herramienta de mediación, Edicones Paidós Ibérica, Barcelona.

- SPENGLER, Fabiana Marion (2016). Da jurisdição à mediação: por uma outra cultura no 
tratamento de conflitos, Unijuí, ljuí.

- VASCONCELOS, Carlos Eduardo (2017). Mediação de conflitos e práticas restaurativas, Forense, Rio de Janeiro, Método, São Paulo.

- VEZZULA, Juan Carlos (2001). Mediação: guia para usuários e profissionais, IMAB, São Paulo.

- WARAT, Luis Alberto (2004). Surfando na pororoca: ofício do mediador, Fundação Boiteux, Florianopólis. 